\title{
Editor's Note: Unequal Relations/Influential Transfers
}

Apart from special issues where articles are selected in response to a call, the unified theme focus of a general issue of $D R J$ as reflected in the Editor's Note is more often than not the result of an attempt to formulate, after the fact, what the articles may profitably be seen to share in common. Commonalities are in no way predetermined, but if the artifice of this framing device holds, it may reveal something shared by the authors, something that used to be called a Zeitgeist. The articles in this issue of DRJ may or may not lend themselves to the unifying thread of a common theoretical or conceptual underpinning. But, I propose the ideas of relation and transfer-both unequal and influential-with respect to dance as knowledge. This may refer to the unequal relation between the disciplinary competency of the choreographer and the choreographic ambition of the museum curator; the otherwise abled Parkinsonian dancer and the disparaged concept of beauty in dance discourse; the exchange between digital culture, virtual dance, and the categories of sex, gender, and race in the dancing body itself; or the revising and deepening of our reading of the history of dance in which traditional received values become re-valued in the light of archival evidence.

Erin Brannigan's "Dance and the Gallery: Curation as Revision” continues the discussions of the "Dance in the Museum" issue (DRJ 46/3). Brannigan questions the extension of the choreographic into the gallery setting, and interrogates the consequences of "the overexpanded concept of "the choreographic" that has served to veil the influence of dance on visual art since the early twentieth century. Brannigan points to the challenges of revising the history of a relation that is now being made visible but is also distorted in the gallery context. The relocation of dance to the visual art site of display in the museum implies a deskilling of the choreographer whose function is now appropriated by the curator. The drive to extinguish medium-specificity is considered as another strategy of expropriation of dance as a discipline. The anxiety of influence hangs like a dark cloud over this scene of transference.

Sara Houston's "Feeling Lovely: An Examination of the Value of Beauty for People Dancing with Parkinson's" examines the relation of Parkinsonian dance to the sensation of beauty in the dancer. The instrumental benefits of dance movement in the clinical assessment give no account of the role of aesthetic experience in movement. This absence of relation between dance and beauty that goes hand in hand with a certain and by now familiar disparagement of ballet in dance discourses may therefore call for re-evaluation once the context of ballet is transferred to a chronic degenerative disease. Houston asks what sorts of new relations can be forged between so-called dis-ability and the return of beauty. And, what are the ramifications for dance theory?

Tiffany Barber's "Ghostcatching and After Ghotscatching, Dances in the Dark" concerns the relation between two versions of a work of digital dance and the underlying transfer of Bill T. Jones's improvisation with its virtual rendering through motion capture. Ultimately, the article discusses how digital culture as a "utopian space," which can erase all traces of race, gender, and sexuality from the dancing body, coincides with a post-racial discourse where race is not longer visually marked. This is complicated by Jones's turn to a formalist approach to choreography in the wake of the Still/Here affair. Barber skillfully teases out the contradictory desires (of Jones as well as of his critics) to 
detach Jones's material body-marked as it is by race, sexuality, and gender-from the virtual body depicted in Ghostcatching and to insist on the impossibility of that detachment.

James Steichen's “The American Ballet's Caravan” provides us with a meticulous, almost moment-by-moment, account of Lincoln Kirstein's activity as a ballet impresario during the first season of Ballet Caravan in 1936. Methodologically, the focus is on institutional analysis combined with a canny sense of aesthetics. In giving close archival attention to an under-studied company and repertory, Steichen does important work in fleshing out a more thorough and developed history of an early formative period in American ballet history-one in which the Balanchine-Kirstein endeavor is re-historicized and narrated anew.

I would add in conclusion that an important facet of each article is the institutional setting of the analysis: the museum, the medical profession, race relations in the U.S., and the official history of an influential dance company. Thus, the unequal relations and influential transfers discussed in these pages rely heavily on institutional analysis in relation to an aesthetic project or the necessity to reconceive an aesthetic project. By the same token, the importance of a disciplinary framework for dance as medium seems to be reasserted here at a variety of levels.

As many readers may know, our cherished colleague Randy Martin passed away this January. Social Text will publish a Denkbild dedicated to Randy in August 2015 (Social Text 33.3 (124), forthcoming). Randy was also closely associated with $D R J$ as an author, reader, and advisory board member. Please see the Call for Submissions here for a special issue of $D R J$ on Randy Martin and Dance Studies.

Mark Franko

Editor, $D R J$

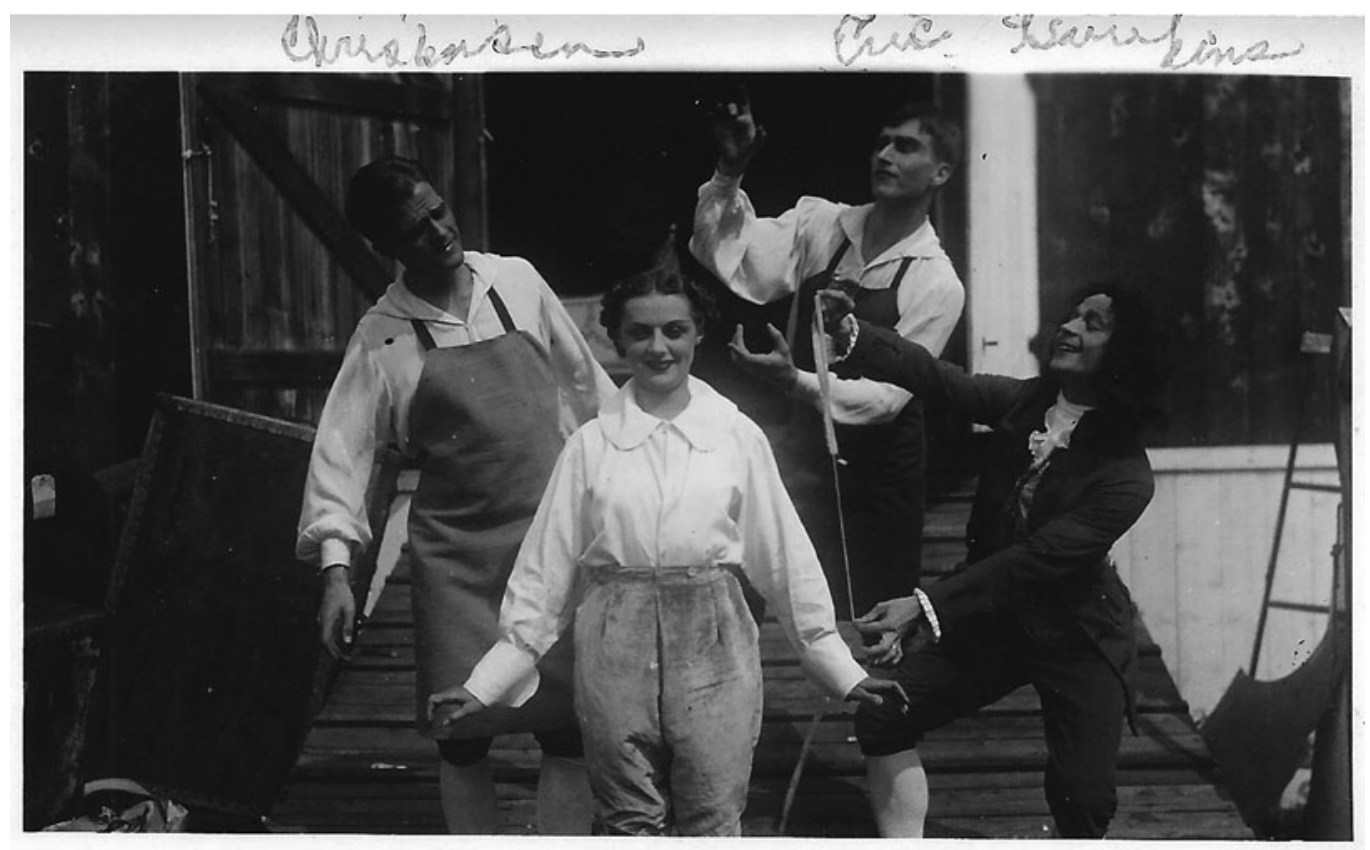

